\title{
Bobbing and hand line fishing methods of Ratnagiri, Maharashtra
}

MAYURI U. DONGARE, ASHISH S. MOHITE, MAKARAND T. SHARANGDHAR AND SHRIKANT T. SHARANGDHAR

\begin{abstract}
The present study encompasses some line fishing methods practiced in Ratnagiri, Maharashtra. The bobbing line locally known as Sarsara was operated at a depth ranging from 10 to $18 \mathrm{~m}$ to catch Scad fish (Kokeri). Its main line was made up of PA monofilament twine of length varying from 6 to $12 \mathrm{~m}$ and diameter ranging from 0.16 to $0.25 \mathrm{~mm}$. Bob was made up of 15 to $30 \mathrm{~cm}$ PA monofilament of same specification as that of the line. Hand line consisting of a line and bait with hook was operated at a water depth of 4.5 to $12 \mathrm{~m}$ and was made up of PA monofilament twine having a twine diameter varying from 0.23 to $1 \mathrm{~mm}$ of length ranging from 5 to $16 \mathrm{~m}$. Barbed 'J' shaped steel hooks of 7 to 13 number were normally used.
\end{abstract}

KEY WORDS : Line fishing methods, Bobbing, Hand line

How to cite this Article : Dongare, Mayuri U., Mohite, Ashish S., Sharangdhar, Makarand T. and Sharangdhar, Shrikant T. (2016). Bobbing and hand line fishing methods of Ratnagiri, Maharashtra. Engg. \& Tech. in India, 7 (2) : 65-72; DOI : 10.15740/HAS/ETI/7.2/ 65-72. 